\title{
Riviciclib Hydrochloride
}

National Cancer Institute

\section{Source}

National Cancer Institute. Riviciclib Hydrochloride. NCI Thesaurus. Code C141429.

The hydrochloride salt form of riviciclib, a flavone and cyclin dependent kinase (CDK) inhibitor with potential antineoplastic activity. Riviciclib selectively binds to and inhibits Cdk4/cyclin D1, Cdk1/cyclin B and Cdk9/cyclin T1, serine/threonine kinases that play key roles in the regulation of the cell cycle and cellular proliferation. Inhibition of these kinases leads to cell cycle arrest during the G1/S transition, thereby leading to an induction of apoptosis, and inhibition of tumor cell proliferation. 